\title{
Supporting Information for: \\ Effect of Humidity and Impurities on the Electrochemical Window of Ionic Liquids and Its Implications for Electroanalysis
}

\author{
Authors and affiliations \\ Simon Doblinger ${ }^{\mathrm{a}}$, Taylor J. Donati ${ }^{\mathrm{a}}$, Debbie S. Silvester ${ }^{\mathrm{a}, *}$ \\ ${ }^{a}$ Curtin Institute for Functional Molecules and Interfaces, School of Molecular and Life Sciences, \\ Curtin University, GPO Box U1987, Perth, WA 6845, Australia \\ *Corresponding author. Email: d.silvester-dean@curtin.edu.au Phone: +61 892667148
}


Table S1. Anodic ( $\left.E W_{\text {pos }}\right)$ and cathodic ( $\left.E W_{\text {neg }}\right)$ potentials (vs the integrated platinum pseudo-reference electrode), as well as total electrochemical windows of nine RTILs at cutoff currents of $15 \mu \mathrm{A}$ at $<1 \mathrm{RH} \%, 1.5 \mu \mathrm{A}$ at $<1 \mathrm{RH} \%$ and $1.5 \mu \mathrm{A}$ at $>95$ RH\%.

\begin{tabular}{|c|c|c|c|c|c|c|c|c|c|}
\hline \multirow[b]{2}{*}{ RTIL } & \multicolumn{3}{|c|}{$I_{\text {cutoff }}=15 \mathrm{uA},<1 \mathrm{RH} \%$} & \multicolumn{3}{|c|}{$I_{\text {cutoff }}=1.5 \mathrm{uA},<1 \mathrm{RH} \%$} & \multicolumn{3}{|c|}{$I_{\text {cutoff }}=1.5 \mathrm{uA},>95 \mathrm{RH} \%$} \\
\hline & $\begin{array}{l}\mathrm{EW}_{\text {pos }} / \\
\mathrm{V}\end{array}$ & $\begin{array}{l}\mathrm{EW}_{\text {neg }} / \\
\mathrm{V}\end{array}$ & $\begin{array}{l}\mathrm{EW}_{\text {total }} \\
/ \mathrm{V}\end{array}$ & $\begin{array}{l}\mathrm{EW}_{\text {pos }} / \\
\mathrm{V}\end{array}$ & $\begin{array}{l}\mathrm{EW}_{\text {neg }} / \\
\mathrm{V}\end{array}$ & $\begin{array}{l}\mathrm{EW}_{\text {total }} \\
/ \mathrm{V}\end{array}$ & $\begin{array}{l}\mathrm{EW}_{\mathrm{pos}} / \\
\mathrm{V}\end{array}$ & $\begin{array}{l}\mathrm{EW}_{\text {neg }} / \\
\mathrm{V}\end{array}$ & $\begin{array}{l}\mathrm{EW}_{\text {total }} \\
/ \mathrm{V}\end{array}$ \\
\hline$\left[\mathrm{S}_{2,2,1}\right]\left[\mathrm{NTf}_{2}\right]$ & 2.5 & -2.5 & 5.0 & 1.2 & -2.3 & 3.5 & 0.6 & -1.5 & 2.1 \\
\hline$\left[\mathrm{N}_{4,1,1,1}\right]\left[\mathrm{NTf}_{2}\right]$ & 2.7 & -3.2 & 5.9 & 1.5 & -2.6 & 4.1 & 0.5 & -1.8 & 2.3 \\
\hline$\left[\mathrm{C}_{4} \mathrm{mpyrr}\right]\left[\mathrm{NTf}_{2}\right]$ & 2.8 & -3.1 & 5.9 & 2.5 & -3.1 & 5.6 & 0.9 & -1.4 & 2.3 \\
\hline [C4mpyrr][FAP $]$ & 3.1 & -3.4 & 6.5 & 2.3 & -3.1 & 5.4 & 1.1 & -1.5 & 2.6 \\
\hline$\left[\mathrm{C}_{2} \mathrm{mim}\right]\left[\mathrm{NTf}_{2}\right]$ & 2.2 & -2.1 & 4.3 & 1.9 & -1.7 & 3.6 & 0.9 & -1.1 & 2.0 \\
\hline$\left[\mathrm{C}_{4} \mathrm{mim}\right]\left[\mathrm{BF}_{4}\right]$ & 2.9 & -1.5 & 4.4 & 2.1 & -1.4 & 3.5 & 1.0 & -0.8 & 1.8 \\
\hline$\left[\mathrm{C}_{4} \mathrm{mim}\right]\left[\mathrm{PF}_{6}\right]$ & 2.7 & -2.1 & 4.8 & 2.1 & -1.5 & 3.6 & 1.1 & -1.0 & 2.1 \\
\hline$\left[\mathrm{C}_{4} \mathrm{mim}\right]\left[\mathrm{NTf}_{2}\right]$ & 2.3 & -2.4 & 4.7 & 2.2 & -1.6 & 3.8 & 1.0 & -1.2 & 2.2 \\
\hline$\left[\mathrm{C}_{4} \mathrm{mim}\right][\mathrm{FAP}]$ & 3.1 & -2.1 & 5.2 & 2.6 & -1.9 & 4.5 & 1.1 & -1.5 & 2.6 \\
\hline
\end{tabular}



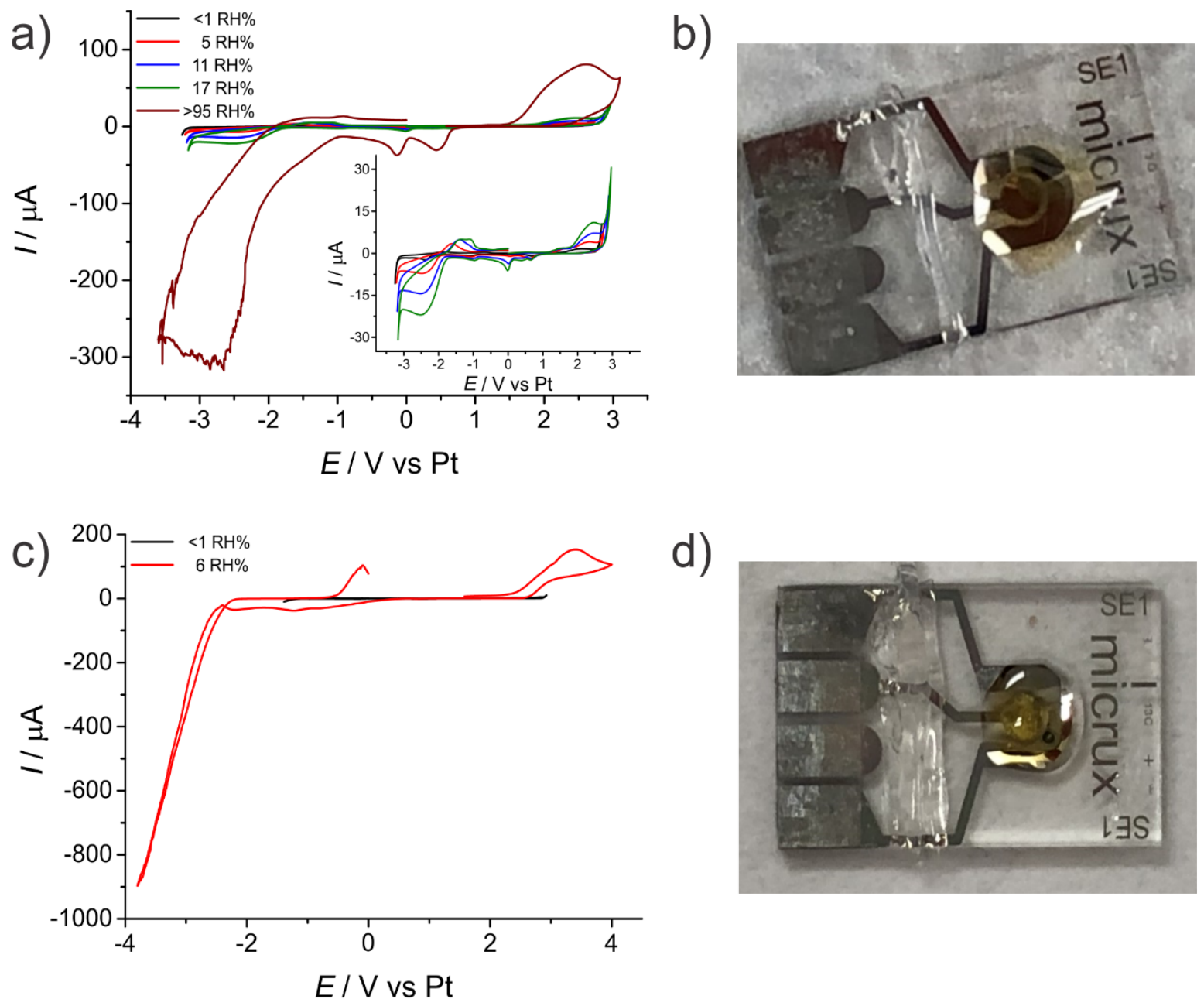

d)

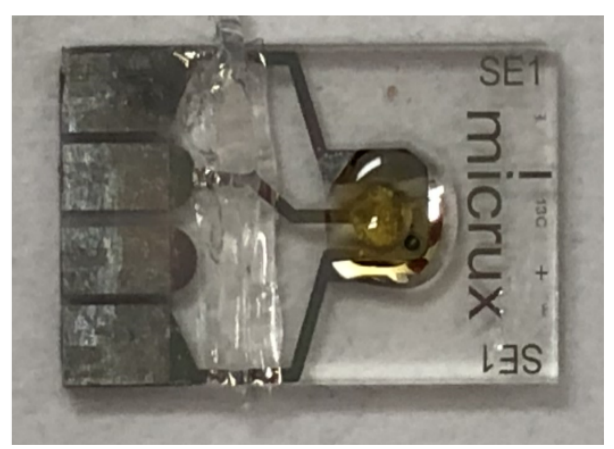

Figure S1. Cyclic voltammetry over a very wide potential range in (a) $\left[C_{4} m p y r r\right]\left[N T f_{2}\right]$ and (c) $\left[C_{4} m i m\right]\left[B F_{4}\right]$ on a Pt-TFE at a scan rate of $100 \mathrm{mV} \mathrm{s}^{-1}$ at different relative humidity levels (RH\%). Photos of the electrodes and the electrolytes after the experiment ((b) and (d)), after scanning the extended potential range at increased humidity levels.

All nine RTILs showed a similar trend of reduced electrochemical windows with increasing relative humidity, as shown in Figure 2 in the main text. To support the suggestion that the cathodic and anodic limits of the electrochemical window is determined by the water oxidation and reduction, further studies were performed. The potentials were scanned to more positive and more negative values to see whether the current increases continuously, or if the current plateaus once the water has been electrolysed.

Figure $\mathrm{S} 1$ shows $\mathrm{CV}$ over a wide potential range for $\left[\mathrm{C}_{4} \mathrm{mpyrr}\right]\left[\mathrm{NTf}_{2}\right]$ and $\left[\mathrm{C}_{4} \mathrm{mim}\right]\left[\mathrm{BF}_{4}\right]$ on a Pt-TFE at a scan rate of $100 \mathrm{mV} \mathrm{s}^{-1}$ at different humidity levels and photos of the electrodes after the wide-scan experiment. For the more hydrophobic $\left[\mathrm{C}_{4}\right.$ mpyrr] $\left[\mathrm{NTf}_{2}\right]$ (Figure S1a), the electrochemical window between 3 and $-3.2 \mathrm{~V}$ was scanned in the 'dry' and the 'humidified' conditions. In contrast to the CV scans illustrated in Figure 2, the potential at which the scan was reversed was kept constant for all cases and no cutoff current was applied. The inset shows a gradual increase of the $\mathrm{CV}$ response at the cathodic and anodic limit of the electrochemical window with increasing humidity level. At the maximum relative humidity (>95 $\mathrm{RH} \%$ ), the $\mathrm{CV}$ response at the negative potential became significantly noisier, which is most likely cause by the hydrogen bubble formation at the electrode. At these wide potential 
ranges, consecutive scanning also causes a degradation of the ionic liquid, illustrated by a colour change from colourless to brown (see Figure S1b).

For $\left[\mathrm{C}_{4} \mathrm{mim}\right]\left[\mathrm{BF}_{4}\right]$, which is fully miscible with water, the same study was attempted. However, at only $6 \mathrm{RH} \%$, one wide scan (red line in Figure S1c) resulted in the browning of the RTIL (Figure S1d), suggesting that at this humidity level, a large concentration of water is already present. It is therefore not advisable to scan very positive or very negative potentials if water is present in the RTIL, due to the build-up of unwanted electrogenerated products. It is known that the tetrafluoroborate anion is not electrochemically stable in the presence of water and ionic liquids based on this anion are highly hygroscopic. ${ }^{1}$ This suggests that the electrochemical window of completely dry $\left[\mathrm{BF}_{4}\right]^{-}$-based RTILs should be significantly larger (as predicted by computational caluclations ${ }^{2}$ ), however the high water contents (and lower current cutoffs) result in smaller experimentally measured EWs. 


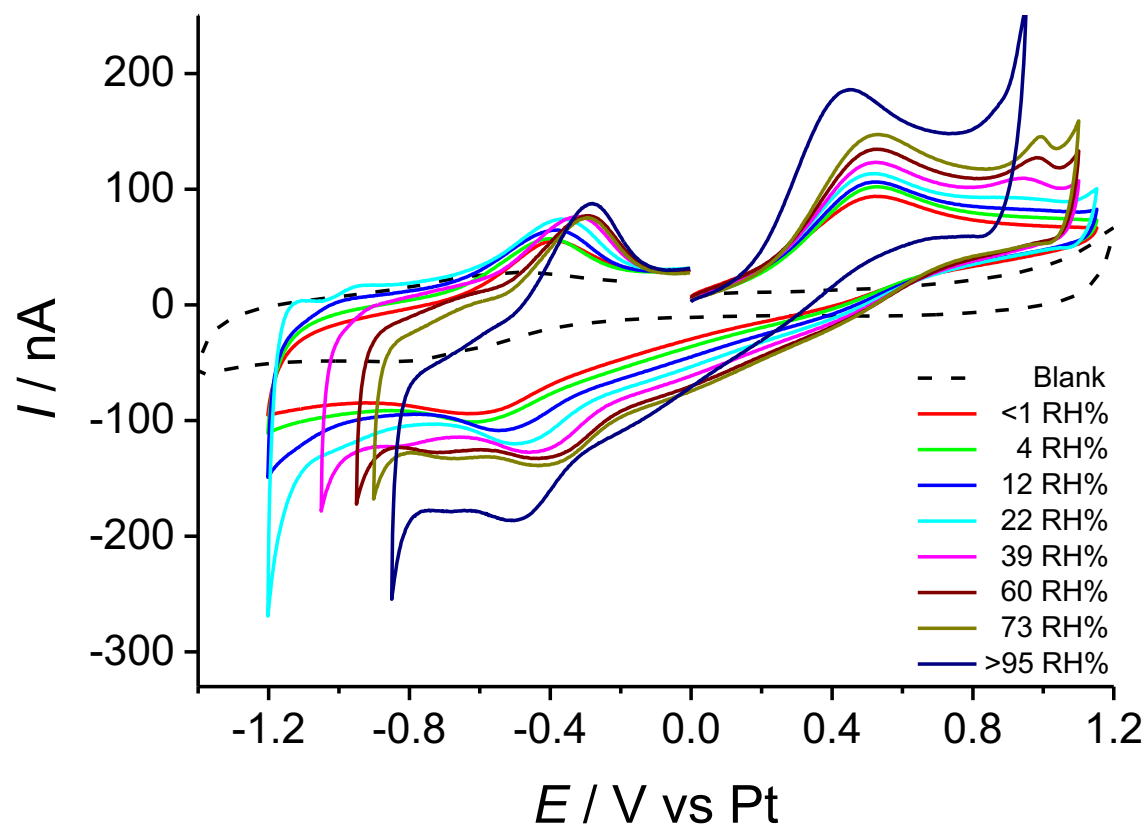

Figure S2. Cyclic voltammetry response for the oxidation of 200 ppm of ammonia gas in $\left[C_{4}\right.$ mpyrr][NTf 2$]$ on a Pt-TFE at a scan rate of $100 \mathrm{mV} \mathrm{s}^{-1}$ at different relative humidity levels (RH\%). The dashed line represents the blank in the absence of ammonia gas at $<1 \mathrm{RH} \%$. 

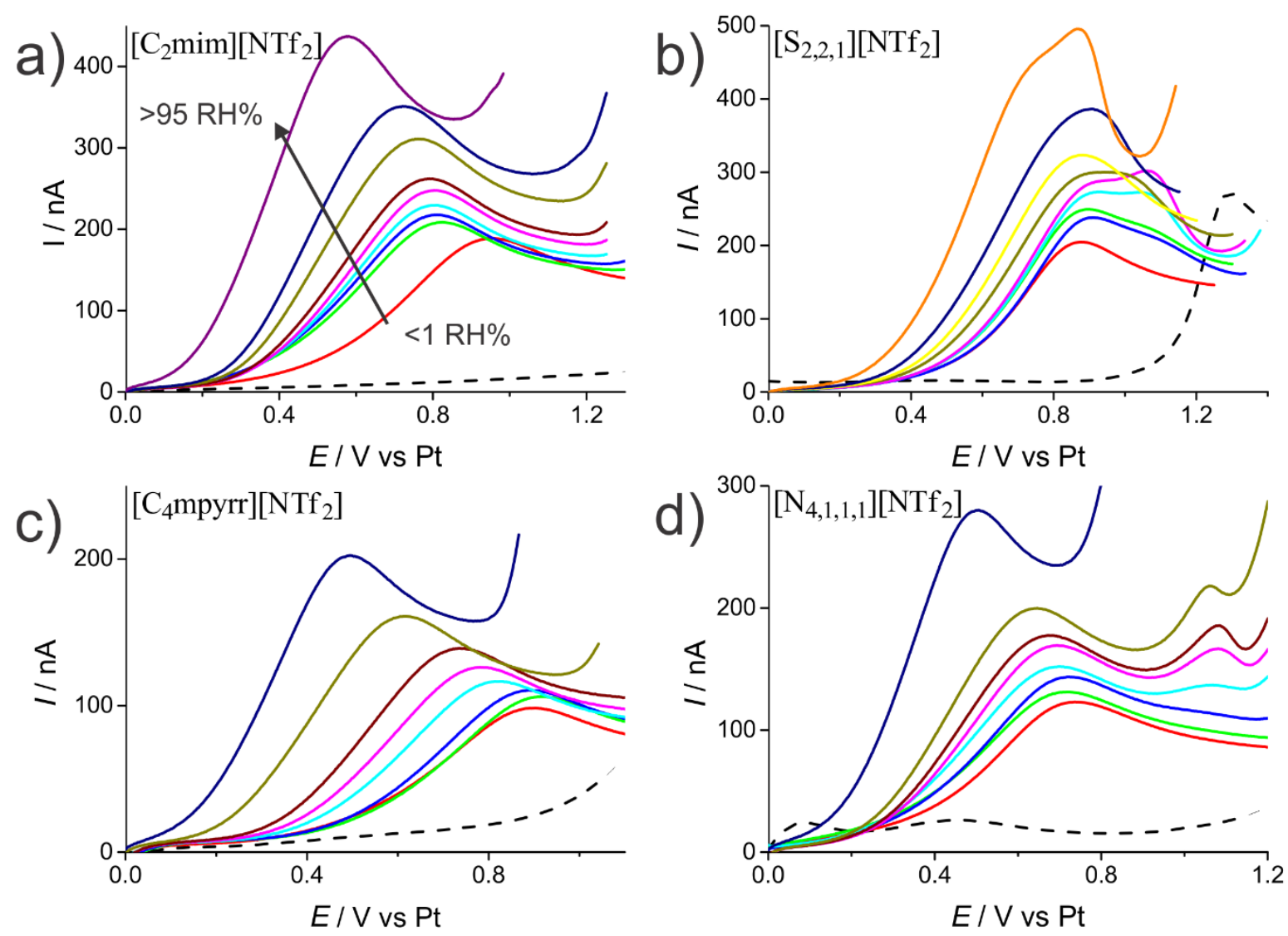

Figure S3. Linear sweep voltammetry for the oxidation of 200 ppm of ammonia gas in a) $\left[C_{2}\right.$ mim] [NTf $\left.f_{2}\right]$, b) $\left[S_{2,2,1}\right]\left[N T f_{2}\right]$, c) $\left[\mathrm{C}_{4}\right.$ mpyrr] $\left[\mathrm{NTf}_{2}\right]$ and d) $\left[\mathrm{N}_{4,1,1,1}\right]\left[N T f_{2}\right]$ on a Pt-TFE at a scan rate of $100 \mathrm{mV} \mathrm{s}^{-1}$ at different humidity levels (RH\%). The dashed line represents the scan in the absence of ammonia gas at $<1 \mathrm{RH} \%$.
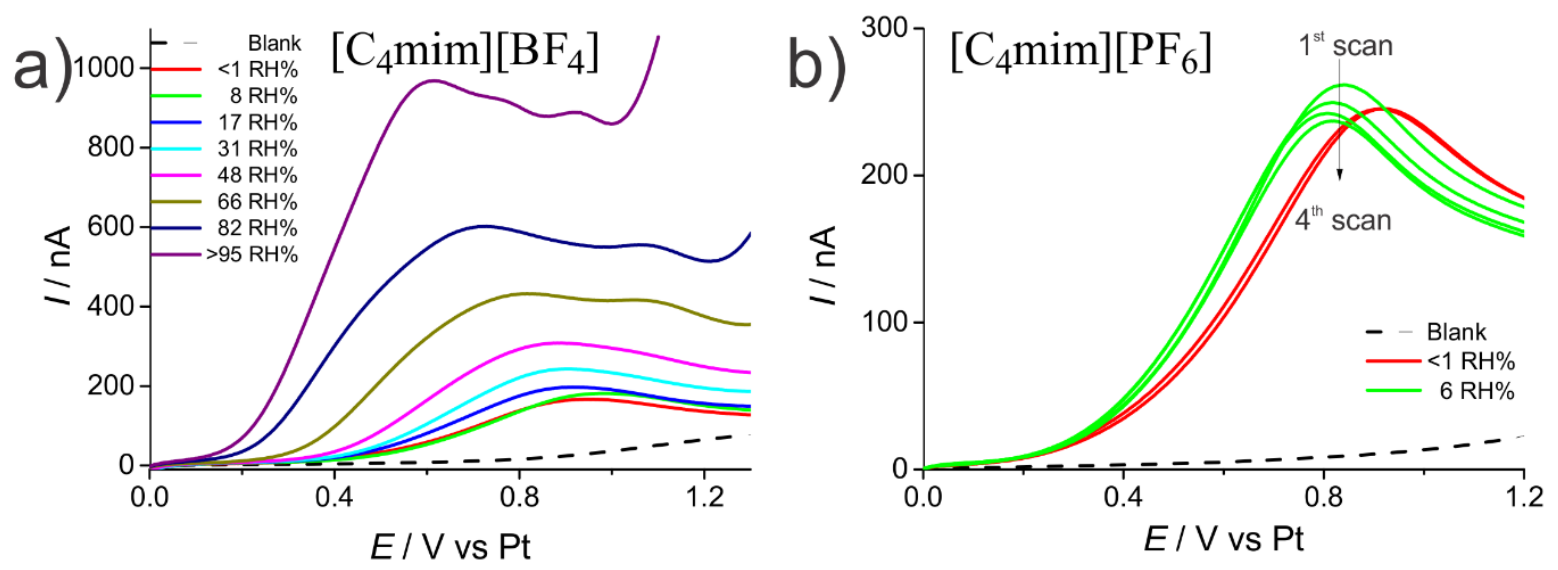

Figure S4. Linear sweep voltammetry for the oxidation of 200 ppm of ammonia gas in a) $\left[\mathrm{C}_{4} \mathrm{mim}\right]\left[\mathrm{BF}_{4}\right]$ and b) $\left[\mathrm{C}_{4} \mathrm{mim}\right]\left[\mathrm{PF}_{6}\right]$ on a Pt-TFE at a scan rate of $100 \mathrm{mV} \mathrm{s}^{-1}$ at different humidity levels (RH\%). The dashed line represents the blank in the absence of ammonia gas. 
$\left[\mathrm{BF}_{4}\right]^{-}$and $\left[\mathrm{PF}_{6}\right]^{-}$anions are known to be hydrolytically unstable, and typically, ionic liquids containing these anions are highly hygroscopic. ${ }^{1}$ Dry $\left[\mathrm{C}_{4} \mathrm{mim}\right]\left[\mathrm{BF}_{4}\right]$ forms strong cation-anion networks, however, in the presence of water, these networks change due to strong hydrogen bond interactions between the tetrahedral $\left[\mathrm{BF}_{4}\right]^{-}$and the pseudo-tetrahedral water network. ${ }^{3}$ Therefore, at high humidity levels, the water content is so high that water-anion interactions dominate over ionic liquid cation-anion interactions, where the electrolyte composition is believed to change from "water-in-RTIL"-like to "RTIL-in-water". LSV for ammonia oxidation at different humidities in $\left[\mathrm{C}_{4} \mathrm{mim}\right]\left[\mathrm{BF}_{4}\right]$ is shown in Figure S4a. A large increase in current is observed (approximately 6 times) from 'dry' $(<1 \mathrm{RH} \%)$ to 'humidified' ( $>95 \mathrm{RH} \%$ ) conditions. It is noted that this RTIL is the only one in the study that is fully miscible with water, so it is likely a very large amount of water present ${ }^{4}$, and the effect of water on the RTIL may be much more complicated than simply a change in the transport properties.

For ammonia oxidation in $\left[\mathrm{C}_{4} \mathrm{mim}\right]\left[\mathrm{PF}_{6}\right]$, the current was observed to reduce on successive scans, even at low humidity levels (see Figure S4b), which means that accurate currents cannot be recorded. Unusual behaviour for ammonia oxidation in this RTIL has been reported previously. ${ }^{5}$ Because of the unstable currents for ammonia oxidation in this RTIL, this data was not included in the discussion in the main manuscript.

\section{References}

1. Freire, M. G.; Neves, C. M. S. S.; Marrucho, I. M.; Coutinho, J. A. P.; Fernandes, A. M., Hydrolysis of Tetrafluoroborate and Hexafluorophosphate Counter Ions in Imidazolium-Based Ionic Liquids. J. Phys. Chem. A 2010, 114, 3744-3749.

2. Kazemiabnavi, S.; Zhang, Z.; Thornton, K.; Banerjee, S., Electrochemical Stability Window of Imidazolium-Based Ionic Liquids as Electrolytes for Lithium Batteries. J. Phys. Chem. B 2016, 120, 5691-5702.

3. Schröder, C.; Rudas, T.; Neumayr, G.; Benker, S.; Steinhauser, O., On the Collective Network of Ionic Liquid/Water Mixtures. I. Orientational Structure. J. Chem. Phys 2007, 127, 234503.

4. O'Mahony, A. M.; Silvester, D. S.; Aldous, L.; Hardacre, C.; Compton, R. G., Effect of Water on the Electrochemical Window and Potential Limits of Room-Temperature Ionic Liquids. $J$. Chem. Eng. Data 2008, 53, 2884-2891.

5. Ji, X.; Silvester, D. S.; Aldous, L.; Hardacre, C.; Compton, R. G., Mechanistic Studies of the Electro-Oxidation Pathway of Ammonia in Several Room-Temperature Ionic Liquids. J. Phys. Chem. C 2007, 111, 9562-9572. 